\title{
Antibiotic Resistance of Helicobacter Pylori and Influencing Factors in Yangzhou, China: a Cross- sectional Study
}

\section{Yun Zhang}

The Affiliated Hospital of Yangzhou University

\section{Xinyi Feng}

The Affiliated Hospital of Yangzhou University

\section{Lijun Bian}

Nanjing Medical University

\section{Yan Zhang}

Nanjing Medical University

\section{Qian Li}

Nanjing Medical University

\section{Yemin Xu}

The Affiliated Hospital of Yangzhou University

\section{Qiang She}

The Affiliated Hospital of Yangzhou University

\section{Caiwang Yan}

Nanjing Medical University

\section{Guotao Lu}

The Affiliated Hospital of Yangzhou University

\section{Jian Wu}

The Affiliated Hospital of Yangzhou University

\section{Weiming Xiao}

The Affiliated Hospital of Yangzhou University

\section{Yanbing Ding}

The Affiliated Hospital of Yangzhou University

Bin Deng ( $\square$ bdeng@yzu.edu.cn )

The Affiliated Hospital of Yangzhou University https://orcid.org/0000-0002-5590-3755

\section{Research}

Keywords: Helicobacter pylori, Antibiotic resistance, VacA, Risk factors 
Posted Date: February 15th, 2021

DOI: https://doi.org/10.21203/rs.3.rs-198405/v1

License: (c) (i) This work is licensed under a Creative Commons Attribution 4.0 International License. Read Full License 


\section{Abstract}

Background: The Helicobacter pylori (H. pylori) antibiotic resistance pattern differs geographically, knowledge of local antimicrobial resistance pattern is key to successful eradication. The current study was performed to investigate the resistance of $\mathrm{H}$. pylori to 5 commonly used antibiotics in Yangzhou.

Methods: A total of 461 H. pylori strains were collected from April 2018 to September 2019 in Yangzhou and tested for their susceptibility to clarithromycin, levofloxacin, metronidazole, amoxicillin, tetracycline using gene chip technology.

Results: The resistance rates of $H$. pylori to clarithromycin, levofloxacin, metronidazole, amoxicillin and tetracycline were $41.0 \%, 44.9 \%, 38.8 \%, 6.3 \%$ and $1.1 \%$. In addition, sixteen multiple resistance patterns were detected, and fortunately there were no strains resistant to all five antibiotics. The vacA s1 allele was detected in each strain, $64.0 \%$ of the isolates were s $1 / \mathrm{m} 2$ genotype, $36.0 \% \mathrm{~s} 1 / \mathrm{m} 1$ genotype. In multivariate analysis, history of chronic superficial gastritis was significantly associated with clarithromycin resistance, strains isolated from subjects with gastrointestinal symptoms had a significantly higher likelihood of metronidazole resistance, and antibiotic resistance of $H$. pylori was independent of both sex and age.

Conclusion: The resistance rate of $H$. pylori to clarithromycin, levofloxacin and metronidazole were very high in Yangzhou, the results will help in selecting effective eradication regimens.

\section{Introduction}

Helicobacter pylori (H. pylori) infection is a common worldwide infection, half of the world's population has been suggested infected with $H$. pylori [1]. Although most people with $H$. pylori infection are asymptomatic, it has been considered associated with chronic gastritis, peptic ulcers, lymphoid tissue lymphoma, and gastric cancer [2,3]. H. pylori eradication treatment can help cure chronic gastritis and reduce the incidence of gastric cancer $[4,5]$. Standard triple therapy with a proton pump inhibitor (PPI) and 2 antimicrobial agents, such as amoxicillin, clarithromycin, or metronidazole, has been considered difficult to achieve the desired eradication rate because of compliance, high gastric acidity, high bacterial load, and bacterial strains, but the key is the increasing $H$. pylori resistance to antibiotics $[4,6]$. Nowadays, bismuth quadruple therapy is recommended as the main empirical treatment therapy in China [7], but it still faces the risk of treatment failure.

The $H$. pylori resistance to antibiotics shows a growing trend over time especially in developing countries, and is related to antibiotic consumption rate in the population. In Korea, the levofloxacin resistance rate of primary strains showed an amazing increase from $4.5 \%$ in $2003-2005$ to $62.2 \%$ in $2017-2018$ [8]. The clarithromycin resistance rate increased from 39.9\% in 2009-2010 to 52.6\% in 2013-2014 in Beijing [9]. Various measures have been taken to face with this severe situation, such as changing therapies, increasing dose, monitoring drug susceptibility. Extensive studies [10-12] have demonstrated that tailored therapy may lead to reduced eradication failures. Current methods to test $H$. pylori resistance to 
antibiotics can be divided into drug sensitivity testing and PCR-based molecular methods. It is well known that strain culture is more difficult to achieve due to time-consuming and technical difficulties, rapid and effective molecular biology methods [13] are increasingly recommended in clinical applications and scientific research. Gene mutation has been regarded as the main reason of antibiotic resistance,which is the basis of molecular methods. It has been reported that point mutations in the peptidyltransferase region encoded in domain $\mathrm{V}$ of $23 \mathrm{~S}$ rRNA gene are responsible for clarithromycin resistance, of which the A2143G and A2142G mutations are the most frequent [14]. Resistance to fluoroquinolones which act by inhibiting the H. pylori DNA gyrase, is due to point mutations in the Quinolones Resistance-Determining Region (QRDR) of the gyrA gene [15]. As for metronidazole resistance, the most prominent claim is that mutations in the gene encoding nitroreductase, such as $r d x A$, frxA, and $\operatorname{fr} x B$, have been reported to be the most important mutation sites [16]. Concerning amoxicillin, mutations of the pbp1 gene are considered as the main cause, the degree of amoxicillin resistance gradually increases with the accumulation of pbp1 mutations [17]. Tetracycline is also one of the antibiotics commonly used in H. pylori eradication, which acts by affecting the $30 \mathrm{~S}$ subunit of the ribosome and blocking aminoacyl-tRNA binding, leading to impaired protein biosynthesis. Tetracycline resistance of $H$. pylori is also caused by mutations in $16 \mathrm{~S}$ rDNA, particularly at positions $926-928[18,19]$. In our study, it was considered as drug-resistant $H$. pylori strain if the gene mutations mentioned above were detected based on gene chip technology [20].

Several important virulence factors play an important role in initial colonization and tissue destruction of H. pylori such as flagella-mediated motility, urease, babA2, oipA, cytotoxin-associated gene A (cagA) and vacuolating cytotoxin $\mathrm{A}(\operatorname{vacA})[21,22]$. The vacA gene exists in almost all $H$. pylori strains and composed of s-region (s1, s2) and m-region (m1, m2) [23]. Li et al. [24] illustrated a close relationship between vacA and both peptic ulcer and gastric cancer. VacA $\mathrm{s} 1$ genotype leads to a stronger protein production than $\operatorname{vac} A \mathrm{~s} 2$ genotype [25], the $\mathrm{m} 1$ allele, but not $\mathrm{m} 2$, is associated with higher levels of toxin activity and more severe gastric epithelial damage [26]. Moreover, it has been reported a possible relationship between $\operatorname{vac} A$ and antibiotic resistance, a study [27] conducted in Iranian showed strains with vacA s $1 / \mathrm{m} 2$ genotype were detected more frequently in resistant isolates.

Our knowledge about resistance of $H$. pylori to antibiotics always comes from other regions' study, no relevant reports have been found in Yangzhou, a comprehensively monitoring of $H$. pylori antibiotic resistance is urgently required. This study aimed to assess the antibiotic resistance pattern of $H$. pylori strains, which will help in selecting effective eradication regimens of $H$. pylori in Yangzhou in the future.

\section{Materials And Methods}

\section{Isolation of $H$. pylori strains}

Fresh antrum biopsy specimens were taken during endoscopy from citizens with a positive ${ }^{13} \mathrm{C}$-urea breath test $\left({ }^{13} \mathrm{C}-\mathrm{UBT}\right)$. All participants were part of the endoscopic screening program in Yangzhou between April 2018 and September 2019. Informed consent was obtained beforehand. Frozen specimens were thawed first and inoculated onto Columbia agar plates supplemented with $10 \%$ calf blood, antibiotic 
selective supplement ( $5 \mathrm{mg} / \mathrm{L}$ trimethoprim, $10 \mathrm{mg} / \mathrm{L}$ vancomycin, $0.38 \mathrm{mg} / \mathrm{L}$ polymyxin $\mathrm{B})$. These plates were incubated at $37^{\circ} \mathrm{C}$ for $3-5$ days under microaerophilic conditions $(5 \%, 02,10 \% \mathrm{CO} 2$ and $85 \% \mathrm{~N} 2) . \mathrm{H}$. pylori colonies were initially identified by their typical morphology, then transferred the positive growth to a fresh Columbia blood agar plate and incubated for $48-72$ hours. The isolates were frozen at $-80^{\circ} \mathrm{C}$ in brain-heart infusion storage medium containing $20 \%$ glycerol until assayed.

\section{H. pylori strains DNA extraction}

Isolated strains were unfrozen at room temperature. Following the removal of supernatant, the cell

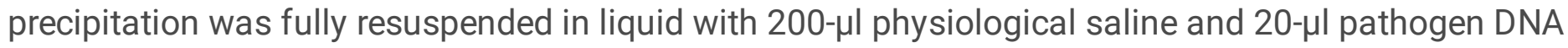
extracting protease $\mathrm{K}$. Nucleic acid extraction was performed according to instruction provided by reagent manufacturer, and isolated DNA was stored at $4^{\circ} \mathrm{C}$.

\section{Polymerase chain reaction}

DNA amplification was performed under the following steps: uracil-DNA glycosylase enzyme reaction at $50^{\circ} \mathrm{C}$ for 10 minutes and pre-denaturation for 10 minutes at $95^{\circ} \mathrm{C}$, then 1 cycle of denaturation at $95^{\circ} \mathrm{C}$ for 30 seconds, extension at $56^{\circ} \mathrm{C}$ for 30 seconds, and a further extension for 30 seconds at $72^{\circ} \mathrm{C}$ by 45 cycles. Followed by the final cycle, primer extension for 5 minutes at $72^{\circ} \mathrm{C}$. The final product of the reaction was stored at $4^{\circ} \mathrm{C}$ till it was analyzed.

\section{Gene chip detection of $H$. pylori}

H. pylori-related gene probes distributed on membrane strips are shown in Table 1. The membranes were put into the 24-well plate sequentially and $1 \mathrm{~mL}$ liquid $\mathrm{A}$ added, preheated in boiling water for 20 minutes, the PCR products were added and hybridized at $48^{\circ} \mathrm{C}$ for 1.5 hours. Aspirated the reaction solution, added $1 \mathrm{~mL}$ pre-warmed liquid $B$, and gently shook at $48^{\circ} \mathrm{C}$ for 15 minutes. The incubation liquid was then discarded. Then gently shook again for 30 minutes at room temperature with incubation solution, and 5 minutes twice with liquid $A$, afterwards washed with liquid $C$ for 1-2 minutes at room temperature. Membranes were then infiltrated in the chromogenic solution, kept in darkness at room temperature for 10 minutes, finally rinsed with pure water to observe the results. 
Table 1

The distribution of $H$. pylori-related gene probes on membrane strips.

\begin{tabular}{|lllll|}
\hline nt926A & nt2142A & 91Asp & 87Asn & 562Asn \\
nt927G & nt2143A & & & \\
nt928A & & & & \\
\hline nt926T & nt2142G & 91Gly & 87Lys & 562Tyr \\
nt927T & & & & \\
nt928C & & & & \\
\hline nt926G & nt2143G & 91Tyr & 91Asn & 562Asp \\
nt927T & & & & \\
nt928A & & & & \\
\hline 556Thr & nt616G & s1 & $m 1$ & UreA \\
\hline 556Ser & nt616A & s2 & $m 2$ & IC \\
\hline
\end{tabular}

\section{Survey questionnaire}

All participants completed the questionnaire prior to esophagogastroduodenoscopy (EGD) that included demographic features (age, sex), smoking and drinking status, gastrointestinal symptoms (heartburn, acid regurgitation, stomach pain, abdominal distension, etc.), previous infection and treatment for $H$. pylori, history of superficial gastritis and first-degree relatives with gastric cancer. In our study, current smoker was defined as consuming $\geq 1$ cigarette per day for more than 1 year and still insisted on smoking at the date of interview or having quit smoking less than 15years. Regularly drinking was defined as drinking alcohol at least once a week and above. History of chronic gastritis was based on previous gastroscopy findings.

\section{Statistical analysis}

All statistical analyses were performed using SPSS statistical software package version 19.0 (SPSS Inc, Chicago, IL, USA). Frequencies and percentages were used to describe the antibiotic resistance rates of $H$. pylori isolates. Categorical variables were first analyzed using the Fisher exact test or $\chi^{2}$ test, and a multivariable logistic regression was also conducted to examine the possible predictors of antibiotic resistance. Two important biological factors, age, sex, were always included in the regression analysis regardless of the statistical significance. For other variables, those who passed a univariate screening with $P$ value $<.20$ were included in this model. A backward variable selection procedure was used to analyze the relationship between the independent variables and dependent variables (antibiotic resistance). Differences with a 2 -tailed $P$ value $<.05$ were considered statistically significant. 


\section{Results}

A total of 461 individuals were included in this study. The subjects' age ranged from 32 to 75 years, with a mean age of $56 \pm 8$ years. $58.4 \%$ (269/461) of these subjects were female and $41.6 \%(192 / 461)$ male. Only 10 participants suffered prior $H$. pylori infection and 6 of them attempted treatment.

\section{H. pylori antibiotic resistance patterns}

Among the 461 isolated strains, 361 (78.3\%) were resistant to at least 1 antibiotic tested. Antibiotic resistance was highest to levofloxacin $(44.9 \%, 207 / 461)$, followed by clarithromycin $(41.0 \%, 189 / 461)$ and metronidazole $(38.8 \%, 179 / 461)$, while amoxicillin $(6.3 \%, 29 / 461)$ and tetracycline $(1.1 \%, 5 / 461)$ had a resistance rate of less than $10 \%$ (Fig. 1).

The pattern of antibiotic resistance is shown in Table 2. Only $21.7 \%(100 / 461)$ of the isolated strains were susceptible to all five antibiotics. Among another 361 strains, $42.3 \%(195 / 461)$ were resistant to more than 1 antibiotic (double, 31.5\%, 145/461; triple, 10.2\%, 47/461; quadruple, 0.7\%, 3/461). In total, sixteen multiple resistance patterns were identified. Among the double resistance, the most common double resistance patterns were CLR + LVX (14.3\%, 66/461), LVX + MTZ $(9.8 \%, 45 / 461)$, and CLR + AMX $(5.9 \%, 27 / 461)$. The main triple resistance patterns were CLR + LVX + MTZ $(6.7 \%, 31 / 461)$ and CLR + LVX $+\operatorname{AMX}(5.9 \%, 12 / 461)$. 
Table 2

Distribution of resistance patterns among $H$. pylori strains $(\mathrm{N}=461)$. CLR, clarithromycin; LVX, levofloxacin; MTZ, metronidazole; AMX, amoxicillin; TET, tetracycline.

\begin{tabular}{|lll|}
\hline Antibiotics & No. of strains & Resistance rate (\%) \\
\hline Sensitive to all antibiotics & 100 & 21.7 \\
\hline CLR & 47 & 10.2 \\
\hline LVX & 45 & 9.8 \\
\hline MTZ & 69 & 15.0 \\
\hline AMX & 5 & 1.1 \\
\hline TET & 0 & 0 \\
\hline CLR + LVX & 66 & 14.3 \\
\hline LVX + MTZ & 45 & 9.8 \\
\hline CLR + MTZ & 27 & 5.9 \\
\hline CLR + AMX & 1 & 0.2 \\
\hline LVX + AMX & 3 & 0.7 \\
\hline LVX + TET & 1 & 0.2 \\
\hline MTZ + AMX & 1 & 0.2 \\
\hline AMX + TET & 1 & 0.2 \\
\hline CLR + LVX + MTZ & 31 & 6.7 \\
\hline CLR + LVX + AMX & 12 & 2.6 \\
\hline CLR + MTZ + AMX & 1 & 0.2 \\
\hline CLR + MTZ + TET & 1 & 0.2 \\
\hline LVX + MTZ + AMX & 1 & 0.2 \\
\hline LVX + AMX + TET & 1 & 100 \\
\hline CLR + LVX + MTZ + AMX & 2 & 0.2 \\
\hline CLR + MTZ + AMX + TET & 1 & 0.2 \\
\hline Total & 461 & \\
\hline
\end{tabular}


Table 3 illustrates the distribution of $H$. pylori vacA genotype in different gastric pathologies. The vacA gene was detected in all 461 strains, with $100 \%$ detection of the s1 allele and no s2 allele was found. $36.0 \%(166 / 461)$ of the strains were detected with $\mathrm{m} 1$ allele, $64.0 \%(295 / 461) \mathrm{m} 2$ allele. The gastric pathologies were divided into 3 groups according to the gastroscopic diagnosis: chronic gastritis/ duodenitis $(88.9 \%, 410 / 461)$; gastric/duodenal ulcer $(9.8 \%, 45 / 461)$; gastric cancer $(1.3 \%, 6 / 461)$. Our findings showed no correlation between vacA genotypes and gastric pathologies $\left(\chi^{2}=2.127, P=0.345\right)$.

Table 3

Distribution of VacA alleles in strains isolated from subjects with different gastric pathologies, $\mathrm{n}$ (\%).

\begin{tabular}{|llllll|}
\hline & $\begin{array}{l}\text { Gastritis/duodenitis } \\
(\mathbf{n = 4 1 0 )}\end{array}$ & $\begin{array}{l}\text { Peptic ulcer } \\
(\mathbf{n = 4 5 )}\end{array}$ & $\begin{array}{l}\text { Gastric cancer } \\
(\mathbf{n}=\mathbf{6})\end{array}$ & $\begin{array}{l}\text { Total } \\
(\mathbf{n}=\mathbf{4 6 1 )}\end{array}$ & Pvalue \\
\hline VacA Alleles & & & & & 0.345 \\
\hline $\mathrm{s} 1 / \mathrm{m} 1$ & $143(34.9)$ & $20(44.4)$ & $3(50)$ & $166(36.0)$ & \\
\hline $\mathrm{s} 1 / \mathrm{m} 2$ & $267(65.1)$ & $25(55.6)$ & $3(50)$ & $295(64.0)$ & \\
\hline
\end{tabular}

\section{Risk factors associated with antibiotic resistance}

Results of univariate analysis of factors associated with antibiotic resistance are summarized in Table 4. We didn't perform the analysis of risk factors associated with amoxicillin and tetracycline resistance, due to their low resistance rates. Gastrointestinal symptoms, history of superficial gastritis and endoscopic findings (ulcer or cancer) were significantly associated with clarithromycin resistance. Strains isolated from people who drunk regularly were more commonly resistant to levofloxacin. What's more, gastrointestinal symptoms, previous history of superficial gastritis and first-degree relatives with gastric cancer were significantly associated with levofloxacin resistance. Metronidazole resistance was found significantly frequent among subjects who had gastrointestinal symptoms. Previous history of superficial gastritis was also associated with metronidazole resistance. Risk factors for resistance to any antibiotic included vacA genotype, alcohol consumption, presence of gastrointestinal symptoms, history of chronic superficial gastritis, and family history of gastric cancer in first-degree relatives. Clarithromycin, levofloxacin, metronidazole, and any antibiotic resistance had no correlation with sex or age.

Multiple logistic analysis showed that resistance to clarithromycin was higher in those with previous history of superficial gastritis. In addition, clarithromycin resistance rate was lower in those diagnosed with peptic ulcer or tumor. In multivariate analysis, drinking, previous history of superficial gastritis and family history of gastric cancer in first-degree relatives were significantly associated with levofloxacin resistance. Gastrointestinal symptoms were significantly associated with resistance to any antibiotics, and this persisted after adjustment by sex, age, vacA genotype, gastrointestinal symptoms, history of superficial gastritis, and family history of gastric cancer in first-degree relatives (Table 5). 


\section{Discussion}

Yangzhou is located in the middle of Jiangsu province, which has a high stomach cancer incidence of 44.05/100000 in 2014 [28]. H. pylori infection is regarded as the major risk factor of stomach cancer, a long-term cohort study [29] from Taiwan, China showed that eradicating $H$. pylori can reduce gastric cancer incidence and mortality. Unfortunately, the high prevalence of $H$. pylori infection and the increasing antibiotic resistance constitute the main challenge for current treatment. The main reason for us to conduct this work is that a disturbing phenomenon was found that a large proportion of people failed to eradicate $H$. pylori during the follow-up investigation, local resistance analysis is urgently required.

First-line eradication treatment is important in China because the rate of $\mathrm{H}$. pylori reinfection after successful treatment is low (1.5\% per person-year) [30], while the global annual reinfection rate of $H$. pylori was 3.1\% [31]. It suggests we should choose the most effective therapy to improve first-line eradication rate. Antibiotic resistance rate of $H$. pylori varies among different countries or regions. In Italy in 2016 , resistance rate to clarithromycin was $35.9 \%$ [32], and rate in Korea was $43.7 \%$ [8]. The present study showed that the resistance to clarithromycin (41.0\%) is slightly higher than that in Zhuanghe (31\%) [33] and significantly higher than the reported rate (22.1\%) in the study included a large number of strains from 13 provinces or cities in China [34]. The significantly higher rate of clarithromycin resistance in Yangzhou may be caused by the long-time and wide use in clinical practice which can promote the emergence of drug-resistant bacteria. In addition, unhealthy lifestyle (no handwashing before meals, sharing utensils, etc.) could lead to the transmission of $H$. pylori among the population as well $[35,36]$. According to consensus recommendations [7], levofloxacin-containing regimen is generally suggested to be avoided as an initial treatment, but as an alternative for rescue therapy because of the high rate of drug resistance. Resistance rate to levofloxacin was 38.8\% in Taiwan, China in 2019 [37], and 56\% in an area of China with a high risk of gastric cancer [33]. It is the highest of levofloxacin resistance rate in our study, maybe due to the widely use of quinolones owing to respiratory and urogenital infections. Metronidazole is a 5-nitroimidazole drug that is widely used for general anaerobic infections worldwide. The rate of metronidazole resistance was found to be $38.8 \%$ in this work, which is lower than the average rate $(61 \%)$ of China in a meta-analysis [38].

The prevalence of resistance to amoxicillin was low in this study, concerning with its low rate of adverse reactions, amoxicillin-containing bismuth quadruple therapy can be used as the preferred choice for $H$. pylori eradication therapy. In addition, high-dose dual therapy is becoming familiar to doctors for great efficacy and lower side effects. The study conducted by Song et al. reported that dual therapy (esomeprazole and amoxicillin four times daily) was non-inferior to, and even superior to triple plus bismuth therapy as first-line $H$. pylori eradication treatment[39]. However, the findings are not yet consistent and remains to be confirmed with further studies. Tetracycline also presented a high sensitivity, and it is recommended to replace amoxicillin for people who are allergic to penicillin. Our study showed that $42.3 \%$ of the strains were resistant to at least two antibiotics. The main resistance patterns were clarithromycin + levofloxacin $(14.3 \%)$, clarithromycin + metronidazole $(9.8 \%)$, clarithromycin 
+ levofloxacin + metronidazole (6.7\%). In addition, we also find several quadruple resistance patterns, and no strains resistant to all five antibiotics tested.

The vacA gene is the main virulence factor of $H$. pylori, strains with $v a c A s 1 / \mathrm{m} 1$ genotype are the most cytotoxic, followed by $\mathrm{s} 1 / \mathrm{m} 2$, and $\mathrm{s} 2 / \mathrm{m} 2$ strains were virtually non-toxic [40]. VacA s1 allele was detected in all strains in our study and was predominant in s1/m2 and s1/m1, is similar to the study conducted by Wang et al [41]. The results suggests that the strains in Yangzhou are more pathogenic and more likely to cause clinical disease. However, our statistics showed that the vacA genotype had no association with any gastric diseases, maybe for the reason of a small sample, which needs to be explored in further studies.

Multivariate analysis showed that history of chronic superficial gastritis was associated with clarithromycin resistance. H. pylori is the major cause of chronic gastritis, long -term $\mathrm{H}$. pylori infection and the formation of bacterial biofilms [42] may lead to antibiotic resistance. Subjects with an endoscopic diagnosis of peptic ulcer or cancer have a lower risk of resistance to clarithromycin, which is consistent with a previous study in France [43]. Levofloxacin resistance was significantly associated with alcohol consumption. It is possible that physicians do not prescribe levofloxacin to patients who drink alcohol because of a disulfiram-like reaction, which might contribute to a low levofloxacin resistance rate among drinkers. In addition, in our study, people with family history of first-degree relatives with gastric cancer have a lower possibility of resistance to levofloxacin, it cannot be well explained at this time and needs to be further clarified by other studies. Gastrointestinal symptoms were significantly associated with levofloxacin and any antibiotics resistance, due to these individuals were infected by $H$. pylori early but ignore it. Unfortunately, the $v a c A s 1 / \mathrm{m} 2$ genotype has not been shown to be associated with antibiotic resistance, although it was found more frequently in resistant strains.

Our study has some limitations. Firstly, we only performed endoscopic screening program in two small towns of Yangzhou city and the participants in our study ranged from 32 to 75 years old, with $80.5 \%$ of the population aged 50 years and above, it may not be adequately reflective of the general population. Secondly, our study was conducted using gene chip technology to detect known mutation sites to determine $H$. pylori antibiotic resistance, which may underestimate the antibiotic resistance. In addition, there are no follow-up investigation on $H$. pylori eradication in positive populations, and we will further strengthen observations.

\section{Conclusions}

In conclusion, Clarithromycin, metronidazole and levofloxacin resistance rates were very high and serious multi-drug resistance cases are detected in Yangzhou. In order to achieve $>90 \%$ eradication rate of $H$. pylori in first-line treatment, it is suggested to avoid the combination of the above three antibiotics, individualized therapy likely be the best strategies locally. We should strengthen monitoring antibiotic resistance of $H$. pylori, as well as educate local residents in the next screening activities, to maintain a good lifestyle and seek medical attention in case of uncomfortable symptoms. 


\section{Abbreviations}

H. pylori: Helicobacter pylori, VacA: vacuolating cytotoxin A; PPI: proton pump inhibitor; EGD: esophagogastroduodenoscopy; Cl: Confidence interval; OR: Odds ratio

\section{Declarations}

\section{Acknowledgments}

None

\section{Funding}

This research was supported by grants from the National Natural Science Foundation of China (31800675), from the Key Research and Development Program of Jiangsu Province (BE2019698), from the Yangzhou Science and Technology Project (YZ2020069).

\section{Availability of data and materials}

All data generated or analyzed throughout this research are included in this published article.

\section{Authors' Contributions}

BD and YBD: study concept and design, obtained funding. BD, WMX and GTL: critical revision of the manuscript for important intellectual content. $Y Z$ and $X Y F$ : performed the experiments, analysis of data, statistical analysis, wrote the paper. LJB, YZ, QL, QS and YMX: acquisition of data, analysis of data, statistical analysis. $Y Z, X Y F$, and $C W Y$ : analysis and interpretation of data. $Y Z$ and $X Y F$ contribute equal to this work. All authors read and approved the final manuscript.

\section{Ethics approval and consent to participate}

The protocol was approved by the Ethics Committee of The Affiliated Hospital of Yangzhou University.

\section{Consent for publication}

Not applicable.

\section{Competing interests}

The authors declare that they have no competing interests.

\section{References}

1. Hooi JKY, Lai WY, Ng WK, Suen MMY, Underwood FE, Tanyingoh D, et al. Global Prevalence of Helicobacter pylori Infection: Systematic Review and Meta-Analysis. Gastroenterology. 2017;153:420- 
429.

2. Blaser MJ. Helicobacter pylori and gastric diseases. Bmj. 1998;316:1507-10.

3. Sugano K, Tack J, Kuipers EJ, Graham DY, El-Omar EM, Miura S, et al. Kyoto global consensus report on Helicobacter pylori gastritis. Gut. 2015;64:1353-67.

4. Malfertheiner P, Megraud F, O'Morain CA, Gisbert JP, Kuipers EJ, Axon AT, et al. Management of Helicobacter pylori infection-the Maastricht V/Florence Consensus Report. Gut. 2017;66:6-30.

5. Li WQ, Zhang JY, Ma JL, Li ZX, Zhang L, Zhang Y, et al. Effects of Helicobacter pylori treatment and vitamin and garlic supplementation on gastric cancer incidence and mortality: follow-up of a randomized intervention trial. Bmj. 2019;366:15016.

6. Graham DY, Fischbach L. Helicobacter pylori treatment in the era of increasing antibiotic resistance. Gut. 2010;59:1143-53.

7. Liu WZ, Xie Y, Lu H, Cheng H, Zeng ZR, Zhou LY, et al. Fifth Chinese National Consensus Report on the management of Helicobacter pylori infection. Helicobacter. 2018;23:e12475.

8. Lee JY, Kim N, Nam RH, In Choi S, Lee JW, Lee DH. Primary and secondary antibiotic resistance of Helicobacter pylori in Korea from 2003 to 2018. Helicobacter. 2019;24:e12660.

9. Zhang YX, Zhou LY, Song ZQ, Zhang JZ, He LH, Ding Y. Primary antibiotic resistance of Helicobacter pylori strains isolated from patients with dyspeptic symptoms in Beijing: a prospective serial study. World J Gastroenterol. 2015;21:2786-92.

10. Zhou L, Zhang J, Song Z, He L, Li Y, Qian J, et al. Tailored versus Triple plus Bismuth or Concomitant Therapy as Initial Helicobacter pylori Treatment: A Randomized Trial. Helicobacter. 2016;21:91-9.

11. Thung I, Aramin H, Vavinskaya V, Gupta S, Park JY, Crowe SE, et al. Review article: the global emergence of Helicobacter pylori antibiotic resistance. Aliment Pharmacol Ther. 2016;43:514-33.

12. Park CS, Lee SM, Park CH, Koh HR, Jun CH, Park SY, et al. Pretreatment antimicrobial susceptibilityguided vs. clarithromycin-based triple therapy for Helicobacter pylori eradication in a region with high rates of multiple drug resistance. Am J Gastroenterol. 2014;109:1595-602.

13. Owen RJ. Molecular testing for antibiotic resistance in Helicobacter pylori. Gut. 2002;50:285-9.

14. De Francesco V, Margiotta M, Zullo A, Hassan C, Giorgio F, Burattini O, et al. Prevalence of primary clarithromycin resistance in Helicobacter pylori strains over a 15 year period in Italy. J Antimicrob Chemother. 2007;59:783-5.

15. Miyachi H, Miki I, Aoyama N, Shirasaka D, Matsumoto Y, Toyoda M, et al. Primary levofloxacin resistance and gyrA/B mutations among Helicobacter pylori in Japan. Helicobacter. 2006;11:243-9.

16. Jenks PJ, Ferrero RL, Labigne A. The role of the $\operatorname{rdxA}$ gene in the evolution of metronidazole resistance in Helicobacter pylori. J Antimicrob Chemother. 1999;43:753-8.

17. Tseng YS, Wu DC, Chang CY, Kuo CH, Yang YC, Jan CM, et al. Amoxicillin resistance with betalactamase production in Helicobacter pylori. Eur J Clin Invest. 2009;39:807-12.

18. Dailidiene D, Bertoli MT, Miciuleviciene J, Mukhopadhyay AK, Dailide G, Pascasio MA, et al. Emergence of tetracycline resistance in Helicobacter pylori: multiple mutational changes in 16S 
ribosomal DNA and other genetic loci. Antimicrob Agents Chemother. 2002;46:3940-6.

19. Trieber CA, Taylor DE. Mutations in the $16 \mathrm{~S}$ rRNA genes of Helicobacter pylori mediate resistance to tetracycline. J Bacteriol. 2002;184:2131-40.

20. Xuan SH, Wu LP, Zhou YG, Xiao MB. Detection of clarithromycin-resistant Helicobacter pylori in clinical specimens by molecular methods: A review. J Glob Antimicrob Resist. 2016;4:35-41.

21. Chen YL, Mo XQ, Huang GR, Huang YQ, Xiao J, Zhao LJ, et al. Gene polymorphisms of pathogenic Helicobacter pylori in patients with different types of gastrointestinal diseases. World $\mathrm{J}$ Gastroenterol. 2016;22:9718-9726.

22. Šterbenc A, Jarc E, Poljak M, Homan M. Helicobacter pylori virulence genes. World J Gastroenterol. 2019;25:4870-4884.

23. Atherton JC, Cao P, Peek RM, Jr., Tummuru MK, Blaser MJ, Cover TL. Mosaicism in vacuolating cytotoxin alleles of Helicobacter pylori. Association of specific vacA types with cytotoxin production and peptic ulceration. J Biol Chem. 1995;270:17771-7.

24. Li Q, Liu J, Gong Y, Yuan Y. Serum VacA antibody is associated with risks of peptic ulcer and gastric cancer: A meta-analysis. Microb Pathog. 2016;99:220-228.

25. McClain MS, Beckett AC, Cover TL. Helicobacter pylori Vacuolating Toxin and Gastric Cancer. Toxins (Basel). 2017;9.

26. Atherton JC, Peek RM, Jr., Tham KT, Cover TL, Blaser MJ. Clinical and pathological importance of heterogeneity in vacA, the vacuolating cytotoxin gene of Helicobacter pylori. Gastroenterology. 1997;112:92-9.

27. Farzi N, Yadegar A, Sadeghi A, Asadzadeh Aghdaei H, Marian Smith S, Raymond J, et al. High Prevalence of Antibiotic Resistance in Iranian Helicobacter pylori Isolates: Importance of Functional and Mutational Analysis of Resistance Genes and Virulence Genotyping. J Clin Med. 2019;8.

28. Han RQ, Wu M, Luo PF, Yu H, Zheng RS, Zhou JY. [Report of cancer incidence and mortality in Jiangsu Province in 2013]. Zhonghua Yu Fang Yi Xue Za Zhi. 2017;51:703-710.

29. Chiang TH, Chang WJ, Chen SL, Yen AM, Fann JC, Chiu SY, et al. Mass eradication of Helicobacter pylori to reduce gastric cancer incidence and mortality: a long-term cohort study on Matsu Islands. Gut. 2021;70:243-250.

30. Xie Y, Song C, Cheng H, Xu C, Zhang Z, Wang J, et al. Long-term follow-up of Helicobacter pylori reinfection and its risk factors after initial eradication: a large-scale multicentre, prospective open cohort, observational study. Emerg Microbes Infect. 2020;9:548-557.

31. Hu Y, Wan JH, Li XY, Zhu Y, Graham DY, Lu NH. Systematic review with meta-analysis: the global recurrence rate of Helicobacter pylori. Aliment Pharmacol Ther. 2017;46:773-779.

32. Fiorini G, Zullo A, Saracino IM, Pavoni M, Vaira D. Antibiotic resistance pattern of Helicobacter pylori strains isolated in Italy during 2010-2016. Scand J Gastroenterol. 2018;53:661-664.

33. Wang D, Guo Q, Yuan Y, Gong Y. The antibiotic resistance of Helicobacter pylori to five antibiotics and influencing factors in an area of China with a high risk of gastric cancer. BMC Microbiol. 
2019;19:152.

34. Liu DS, Wang YH, Zeng ZR, Zhang ZY, Lu H, Xu JM, et al. Primary antibiotic resistance of Helicobacter pylori in Chinese patients: a multiregion prospective 7-year study. Clin Microbiol Infect. 2018;24:780.e5-780.e8.

35. Monno R, De Laurentiis V, Trerotoli P, Roselli AM, lerardi E, Portincasa P. Helicobacter pylori infection: association with dietary habits and socioeconomic conditions. Clin Res Hepatol Gastroenterol. 2019;43:603-607.

36. Brown LM, Thomas TL, Ma JL, Chang YS, You WC, Liu WD, et al. Helicobacter pylori infection in rural China: demographic, lifestyle and environmental factors. Int J Epidemiol. 2002;31:638-45.

37. Liang CM, Tai WC, Hsu PI, Wu DC, Kuo CH, Tsay FW, et al. Trend of changes in antibiotic resistance in Helicobacter pylori from 2013 to 2019: a multicentre report from Taiwan. Therap Adv Gastroenterol. 2020;13:1756284820976990.

38. Kuo YT, Liou JM, El-Omar EM, Wu JY, Leow AHR, Goh KL, et al. Primary antibiotic resistance in Helicobacter pylori in the Asia-Pacific region: a systematic review and meta-analysis. Lancet Gastroenterol Hepatol. 2017;2:707-715.

39. Song Z, Zhou L, Xue Y, Suo B, Tian X, Niu Z. A comparative study of 14-day dual therapy (esomeprazole and amoxicillin four times daily) and triple plus bismuth therapy for first-line Helicobacter pylori infection eradication: A randomized trial. Helicobacter. 2020;25:e12762.

40. Miehlke S, Kirsch C, Agha-Amiri K, Günther T, Lehn N, Malfertheiner P, et al. The Helicobacter pylori vacA $s 1, m 1$ genotype and cagA is associated with gastric carcinoma in Germany. Int $\mathrm{J}$ Cancer. 2000;87:322-7.

41. Wang J, van Doorn LJ, Robinson PA, Ji X, Wang D, Wang Y, et al. Regional variation among vacA alleles of Helicobacter pylori in China. J Clin Microbiol. 2003;41:1942-5.

42. Fauzia KA, Miftahussurur M, Syam AF, Waskito LA, Doohan D, Rezkitha YAA, et al. Biofilm Formation and Antibiotic Resistance Phenotype of Helicobacter pylori Clinical Isolates. Toxins (Basel). 2020;12.

43. Mégraud F, Lehn N, Lind T, Bayerdörffer E, O'Morain C, Spiller R, et al. Antimicrobial susceptibility testing of Helicobacter pylori in a large multicenter trial: the MACH 2 study. Antimicrob Agents Chemother. 1999;43:2747-52.

\section{Tables}

Due to technical limitations, table 4 and 5 xlsx are only available as a download in the Supplemental Files section.

\section{Figures}




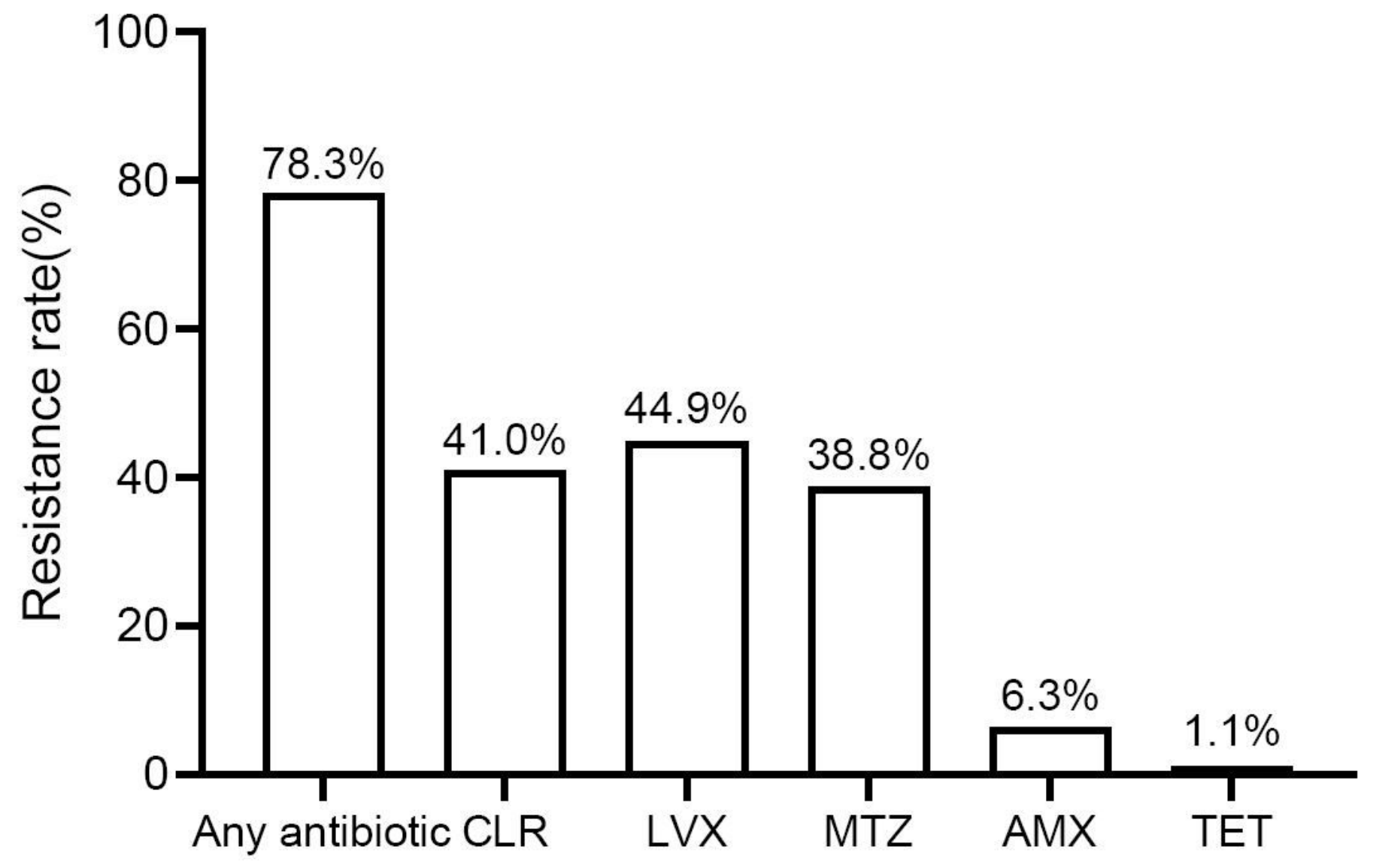

Figure 1

Resistance of $\mathrm{H}$. pylori to clarithromycin, levofloxacin, metronidazole, amoxicillin, tetracycline. CLR, clarithromycin; LVX, levofloxacin; MTZ, metronidazole; AMX, amoxicillin; TET, tetracycline.

\section{Supplementary Files}

This is a list of supplementary files associated with this preprint. Click to download.

- renamed5567c.xlsx

- Table5.xlsx 